\title{
LA XENOFOBIA Y LA CONVIVENCIA INTERCULTURAL: UNA PERSPECTIVA CATÓLICA
}

\author{
Pbro. Robert E. Mosher, sscc. \\ Facultad de Teología \\ PUC de Chile \\ Parroquia Sto. Tomás de Aquino. \\ (La Pintana, Santiago de Chile) \\ rmosher@uc.c
}

Desde los comienzos de la Iglesia-es decir, desde los comienzos del movimiento de creyentes cristianos en el seno del judaísmo-la primera generación de esta comunidad de fe tuvo que enfrentar y asumir el hecho inesperado y desconcertante de que extranjeros querían bautizarse y hacerse miembros de sus asambleas, sin cambiarse la identidad cultural. La crisis provocada por las conversiones de grandes números de gentiles llevó a la antigua Iglesia a declarar, por la voz colectiva de los principales líderes, que no debe imponerse a los conversos las normas del pueblo judíoespecíficamente, sobre la circuncisión y los alimentos. La puerta a una gran variedad de culturas dentro de una sola comunidad de fe se abrió, y desde entonces la Iglesia católica, junto con otras Iglesias y Comunidades que se separaron de ella y entre sí, ha sido constitucionalmente multicultural, y define su razón de ser en términos de acercamientos a todos los pueblos de la tierra-para compartir la Buena Nueva que sus miembros han descubierto en Jesús de Nazaret con literalmente todo el mundo.

Pero no todo ha sido, en la historia de esta comunidad, flores de respeto y aprecio por otras culturas y grupos étnicos, a pesar de tan esperanzador comienzo. La xenofobia-el temor irracional y persistente hacia personas percibidas como étnicamente distintas-puede detectarse sin mucho esfuerzo en períodos asociados con la Iglesia y sus políticas oficiales, o en el contexto de sociedades supuestamente cristianizadas. $\mathrm{Y}$ en estos períodos llama la atención la energía y las acrobacias intelectuales que emplean los xenófobos para hacer de este temor irracional una postura racional, y justificable-y, por ende, convincente para otros potenciales xenófobos.

La estructura centralizada y jerarquizada de la Iglesia católica ha ayudado a frenar, en algunos casos, y corregir tendencias xenofóbicas. En el famoso caso Dreyfus a fines del siglo XIX, la teórica política alemana Hannah Arendt ha descrito con franqueza la complicidad de la Iglesia católica, por sus congregaciones religiosas, en los ataques a la república francesa por su investigación del proceso judicial en contra del primer judío a ascender por los rangos militares altos de esa nación, símbolo vivo de los intentos de asimilación cultural de la población judía en el occidente.

Es un ejemplo del aporte a los sentimientos xenofóbicos que la Iglesia católica pueda, equivocadamente, brindar, pero Arendt también puso énfasis en lo que puso fin a tales escandalosos esfuerzos que contradecían los valores del Evangelio. La campaña antisemita de parte de las organizaciones y los periódicos católicos solamente desapareció, tanto en sectores católicos de la Francia como en Italia, Inglaterra y en los EE.UU. después que apareciera una entrevista periodística con el Papa León XIII.

El Papa Juan Pablo II reconoció estos lamentables episodios en sus escritos y gestos durante el Año Jubilar 2000. Escribió en Tertio Millennio Adveniente no. 35, inmediatamente después de lamentar las divisiones entre los cristianos:

...Otro capítulo doloroso sobre el que los hijos de la lglesia deben volver con ánimo abierto al arrepentimiento está constituido por la aquiescencia manifestada, especialmente en algunos siglos, con métodos de intolerancia e incluso de violencia en el servicio a la verdad. ...Muchos motivos convergen con frecuencia en la creación de premisas de intolerancia, alimentando una atmósfera 
pasional a la que sólo los grandes espíritus verdaderamente libres y llenos de Dios lograban de algún modo substraerse. Pero la consideración de las circunstancias atenuantes no dispensa a la Iglesia del deber de lamentar profundamente las debilidades de tanto hijos suyos, que han desfigurado su rostro, impidiéndole reflejar plenamente la imagen de su Señor crucificado, testigo insuperable de amor paciente y de humilde mansedumbre. De estos tratos dolorosos del pasado emerge una lección para el futuro, que debe llevar a todo cristiano a tener buena cuenta del principio de oro distado por el Concilio: "La verdad no se impone sin por la fuerza de la misma verdad, que penetra, con suavidad y firmeza a la vez, en las almas." ...

Junto con lamentar el profundo abismo económico que separa los países ricos y los empobrecidos, el mismo pontífice hace mención en otro documento magisterial de factores negativos culturales, en Sollicitudo Rei Socialis no. 15:

El cuadro trazado... sería... incompleto, si a los «indicadores económicos y sociales» del subdesarrollo no se añadieran otros igualmente negativos, más preocupantes todavía, comenzando por el plano cultural. Estos son: el analfabetismo, la dificultad o imposibilidad de acceder a los niveles superiores de instrucción, la incapacidad de participar en la construcción de la propia Nación, las diversas formas de explotación y de opresión económica, social, política y también religiosa de la persona humana y de sus derechos, las discriminaciones de todo tipo, de modo especial la más odiosa basada en la diferencia racial. ...

Otros documentos oficiales de la Iglesia ofrecen amplia evidencia de una renovada sensibilidad a la dignidad de cada pueblo (Catecismo de la Iglesia Católica nos. 1934 y ss., por un ejemplo). También, el trabajo pastoral de la Iglesia católica hasta el día de hoy con los inmigrantes-por ejemplo, por INCAMI en Chile-ayuda a la propios católicos a percibir la llegada de extranjeros al país en una buena luz, aunque persisten abusos laborales entre muchos supuestos fieles católicos que los emplean sin contrato escrito.

En el campo de relaciones entre las variadas comunidades cristianas, es notable el punto de vista compartido por algunos católicos, que la presencia de Iglesias y Comunidades protestantes y evangélicos representa la llegada invasora de una cultura extraña a la del continente y sus pueblos tradicionalmente católicos. Pero esta perspectiva se desafía por los estudiosos del fenómeno del crecimiento del movimiento pentecostal, incluyendo al propio San Alberto Hurtado en su obra $i$ Es Chile un país católico?, quienes reconocen que la gran mayoría de comunidades evangélicas en Chile y en otros países latinoamericanos son comunidades pentecostales que han echado sus raíces profundamente en el mundo de los más pobres y marginados, sin vinculación material o cultural alguna con los pueblos de otras naciones. Incluso, las primeras comunidades pentecostales de Chile, todavía las más grandes del mundo pentecostal chileno, fueron compuestas de los expulsados de las comunidades metodistas de origen norteamericano.

Lo que hizo necesario el movimiento ecuménico entre las variadas comunidades cristianas fue la actividad misionera de éstas en el siglo XIX—una actividad que en sí también contribuyó a nuevas actitudes de aprecio por otras culturas y tradiciones espirituales. Los primeros congresos ecuménicos se reunían por temas que promovían mayor cooperación misionera entre las comunidades. La vida misionera de las sociedades y congregaciones cristianas puso a muchos cristianos en conocimiento de la profunda riqueza y sabiduría de muchos pueblos no cristianos, y contribuyó al fomento de mayor respeto por los aportes de la antropología cultural al pensamiento, a la cosmovisión y a la práctica intercultural de la Iglesia católica.

La misma palabra y concepto de "cultura" entró en el lenguaje oficial del magisterio de la Iglesia cuando documentos fundamentales del Concilio Vaticano II (1962-1965) afirmaban el derecho de cada persona a participar de la vida cultural de su pueblo, y promovió un cambio de paradigma sobre la actividad misionera de la Iglesia que permitió afirmar que los misioneros llegaban a las tierras de otros pueblos más para aprender que predicar. La Iglesia fundada en los países alrededor del Mar Mediterráneo aprendió a reconocer que no era necesario convertirse en europeo para ser cristiano.

\footnotetext{
${ }^{1}$ Citación de Dignitatis humanae 1.
} 
La renovación iniciada por este Concilio significó que los creyentes católicos podrían emprender el contacto, y elaborar una relación solidaria, con grupos étnicos y religiosos distintos, en lugar de reaccionar negativamente o mantener la distancia que fomenta la cultivación de actitudes xenofóbicas. Tal contacto debe profundizarse con el estudio y la respetuosa observación, e incluso participación en algunos casos, de las historias y tradiciones ajenas, dejando que una auténtica familiaridad y conocimiento sustituyan los estereotipos falsos y prejuicios inconscientes anteriores.

A esa altura, alcanzando una perspectiva informada y verosímil sobre el otro, el valor cristiano bidimensional de arrepentimiento y conversión llevaría a los creyentes católicos a descartar definitivamente las actitudes y comportamientos que florecieron en la ignorancia sobre el otro, incluyendo el temor y el rechazo a lo nuevo y desconocido. La "Nueva Persona" que todo cristiano desea que nazca en el interior de la propia existencia será una persona más generosa y libre de recelos y odios, llegando a ser semejante a su Maestro, quien supo admirarse de la fe de un soldado romano, o de la mujer extranjera que exigió su derecho a recoger las migas que caían de la mesa de los judíos.

Más importante todavía, en Cristo descubrimos, ocupando una frase de Pablo, que las barreras de todo tipo entre esclavos y libres, hombres y mujeres, judíos y griegos y los pueblos todos se caían, abriendo el camino hacia la constitución de un solo pueblo de fe, unido pero no uniforme, tomado de todas las naciones y vinculado con otras tradiciones espirituales, y con toda persona de recta conciencia (Lumen Gentium ํo 16). Así en la Iglesia nos consideramos en camino hacia la unidad visible con todo cristiano, valorando la diversidad de tradiciones cristianas dentro de un solo Cuerpo de Cristo (otra imagen tradicional por la comunidad cristiana), además de valorar también las variadas maneras de buscar a Dios y de celebrar de generación en generación los dones de belleza, sabiduría y santidad que se han distribuido por todas las culturas de la familia humana.

No se nos pierde la identidad como católicos romanos al abrirnos a reconocer las riquezas de otras tradiciones espirituales, sino todo lo contrario. Ser cristiano católico es precisamente ser una persona de respeto y diálogo, miembro de una comunidad que, como su Maestro, sale al encuentro con el otro, escucha y valora al otro, entable el diálogo con el otro y da ejemplo de cooperación en los esfuerzos comunes de mejorar la vida social, promover los valores comunes, proteger el medio ambiente, instar a establecer las bases de una auténtica paz entre los pueblos, y, lejos de ser utilizada para justificar la violencia y el conflicto entre las naciones, ofrecer una manera de vivir que estrecha la mano hacia el otro, tratando a cada ser humano como le gustaría ser tratado uno mismo. 